\title{
EFFECT OF THE PRESSUE RATIO IN GAS TURBINE FOR POWER GENERATION: AN EXERGY AND THERMODYNAMIC ANALYSIS
}

\author{
Nelly A. De Armas Calderón ${ }^{1}$, Guillermo E. Valencia Ochoa ${ }^{2 *}$, Alfonso Rodríguez Peña ${ }^{3}$ \\ ${ }^{1}$ Mechanical Eng. Student. Research Group on Energy-Efficient Management - kaí, \\ Faculty of Engineering. Barranquilla, Colombia. \\ ${ }^{2} \mathrm{MsC}$. Mechanical Eng. Research Group on Energy-Efficient Management - kaí, \\ Faculty of Engineering. Barranquilla, Colombia. \\ ${ }^{3} \mathrm{MsC}$. Mechanical Eng. Research Group on Materials, \\ Processes and Manufacturing Technologies - IMTEF, Faculty of Engineering.Barranquilla, Colombia. \\ guillermoevalencia@mail.uniatlantico.edu.co
}

\begin{abstract}
This article presents the study of cycle efficiency, exegetical efficiency net work and exergy destroyed by components with the assistance of Power Cycle V.2.0 software, an academic program focused on the practical development of the learning of the power cycles whose language was developed in MATLAB. For the Brayton cycle case,the case studies were based on the behavior of the net work and the efficiency of the cycle with respect to pressure variation at different temperatures, In the same way, the exergy that destroys each component at different pressure ratios was studied, and finally, the exegetical and cycle efficiency at various ratios of pressure and temperature at the turbine inlet was analyzed. From these cases, it was obtained that the thermal efficiency increases as the pressure ratio and the temperature of the turbine inlet increases. This efficiency improves by approximately $12 \%$ compared to the initial conditions. On the other hand, a maximum net workload occurs when the pressure ratio is $\mathbf{1 0}$ and the temperature is at $1500 \mathrm{~K}$. In addition, the turbine and the compressor were the most energy-destroying components in most cases.
\end{abstract}

Keywords: Brayton, power cycles, compressor, energy, exergy, turbine.

\section{INTRODUCTION}

In the operation of industrial processes, engineers are confronted with labor situations that require decision making that requires the handling of fundamental concepts related to thermodynamics and its influential laws[1]. The mastery of these concepts is not only required at an industrial level, but they are involved in many activities that humanity carries out in its daily life, such as the use of transport means that involve the operation of engines, and the residential use of energy that involves the generation in thermal power plants [2].

For this reason, it is necessary to operate thermal power generation plants, where the system does a net work that is transformed in the generator. One of the power cycles that has been widely studied is the Brayton cycle, given its benefits and competitive advantages in the area of aircraft propulsion and electric power generation $[3],[4],[5]$. When it is used in aircraft propulsion, he gas turbine generates enough power to run both the compressor and a small generator, which in turn runs the auxiliary equipment, where the high-speed exhaust gases are responsible for producing the thrust needed to power the aircraft[6]. Gas turbines are also used as stationary power plants that generate electricity as stand-alone units or in conjunction with steam power plants on the high temperature side, where the exhaust gases from the gas turbines serve as a heat source for steam[7],[8].

The Brayton cycle has been studied in detail by engineers with the objective of making them more efficient and generating greater savings [9],[10],[11],[12]. Consequently, the analysis of exergy has also been the subject of great discussion, disseminated in books on advanced thermodynamics for engineering[13],[14],[15]. This has motivated the inclusion of academic software in these topics to be on the rise, which has led to positioning them as essential tools for the development of learning processes in the current century[16], because they encourage the student to a high degree to interdisciplinarity, they also promote cooperative learning, digital and audiovisual literacy, develop information search and selection skills, improve expression and creativity skills, and also allow them to visualize simulations[17]. 
Similarly, with the help of the EES software, positive results were obtained in some thermodynamic case studies, because this software allows the prediction of operating conditions at a maximum coupling ratio in a Brayton cycle. However, this software has a limited accessibility, due to its added costs by its use and licenses[18].

On the other hand, a program called cycles 2005 was developed using the language Visual Basic $6.0{ }^{\circledR}$, offering user-friendly and intuitive screens, which facilitates the use of the program for users with low computer knowledge. However, despite the benefits offered by the above program, it is only available for the study of basic Rankine cycles, with overheating, overheating and regeneration cycles, not considering the more complex cycles[19].

For this reason, the main contribution of this article is to present for the Brayton open cycle the results obtained through the use of a software developed in power cycles, which is completely free and can be used without any restrictions, allowing to calculate the net work, cycle efficiency, exergy destroyed and exegetical efficiency according to the variation of pressure ratio at different temperatures at the turbine inlet.

\section{METHODOLOGY}

For the development of these case studies, the Power Cycle V.2.0 software, a program created by students and professors of Universidad del Atlántico, was indispensable to speed up the thermodynamic calculations, achieving a faster thermodynamic analysis. This program was created with a language in MATLAB, is suitable for any operating system and has a user-friendly interface. For the Brayton cycle, the software is programmed in such a way that the user enters input data, resultingthe properties for each state, and also the efficiency of the cycle.

\subsection{Fundamental equations}

In order to carry out the case studies, it was necessary to program several equations (1-12) such as exergetic and energetic analysis, etc. As shown in Table I, these equations were deduced under the following considerations: stationary state, potential energies and kinetics negligible, the boundary does not perform work and is the same mass flow.

TABLE I. Energy and Exergy balance by components

\begin{tabular}{|c|c|c|c|}
\hline Component & $\begin{array}{l}\text { Energy } \\
\text { Balance }\end{array}$ & Exergy Balance & Efficiency \\
\hline Compressor & $\begin{array}{l}W_{r} \\
=\left(h_{2 r}\right. \\
\left.-h_{1}\right)(1)\end{array}$ & $\begin{aligned} X_{\text {dest }}=W_{\text {ent }}- & {\left[h_{2}-h_{1}\right.} \\
& -T_{0}\left(\dot{s}_{2}-\dot{s}_{1}\right. \\
& \left.-\operatorname{Rln}\left(P_{2} / P_{1}\right)\right]\end{aligned}$ & $\eta=\frac{h_{2 s}-h_{1}}{h_{2 r}-h_{1}}$ \\
\hline $\begin{array}{c}\text { Combustion } \\
\text { Chamber }\end{array}$ & $\begin{array}{l}Q_{\text {in }} \\
=\left(h_{3}\right. \\
\left.-h_{2 r}\right)\end{array}$ & $\begin{aligned} X_{\text {dest }}=\left(1-T_{0} / T\right) & Q_{e n t} \\
& -\left(h_{3}-h_{2}\right. \\
& \left.-T_{0}\left(\dot{s}_{3}-\dot{s}_{1}\right)\right)\end{aligned}$ & \\
\hline \multirow[t]{3}{*}{ Turbine } & $\begin{array}{l}W_{r} \\
=\left(h_{3}\right. \\
\left.-h_{4 r}\right)\end{array}$ & $\begin{aligned} X_{d e s t}=\left[h_{3}-h_{4}\right. & \\
& -T_{0}\left(\dot{s}_{3}-\dot{s}_{4}\right. \\
& \left.-\operatorname{Rln}\left(P_{3} / P_{4}\right)\right]-W_{\text {sal }}(7)\end{aligned}$ & $\eta=\frac{h_{3}-h_{4 r}}{h_{3}-h_{4 s}}(10)$ \\
\hline & & Cycle thermalefficiency $\mid \boldsymbol{\eta}_{\text {ter }}=\frac{W_{\text {neto }}}{Q_{\text {entrada }}}$ & \\
\hline & & Efficiency of second law $\eta_{I I}=\frac{\eta_{t e r m}}{\eta_{\max }}$ & \\
\hline
\end{tabular}

\section{RESULTS AND DISCUSSION}

For the analysis of this cycle, three case studies were taken into consideration and with the help pf the software and the data obtained were plotted for a better understanding.

3.1. Energy by work behavior and cycle efficiency at different pressure ratios.

The initial conditions in the Brayton cycle to study the influence of pressure ratio change $\left(\mathrm{P}_{2} / \mathrm{P}_{1}\right)$ at different temperatures $\mathrm{T}(\mathrm{K})$, in the efficiency ratio of cycle and net work were given as follows. The compressor inlet temperature is $300 \mathrm{~K}$, the pressure ratio initially is 6 , the temperature inlet the turbine is $1000 \mathrm{~K}$ and the turbine and compressor efficiencies are $85 \%$ and $80 \%$ respectively. Measures were taken when the pressure ratio varies a unit in the interval $[6,15]$ at different $T_{3}[1000 \mathrm{~K}, 1300 \mathrm{~K}, 1500 \mathrm{~K}]$, obtaining results as shown in the Figure 1 . 


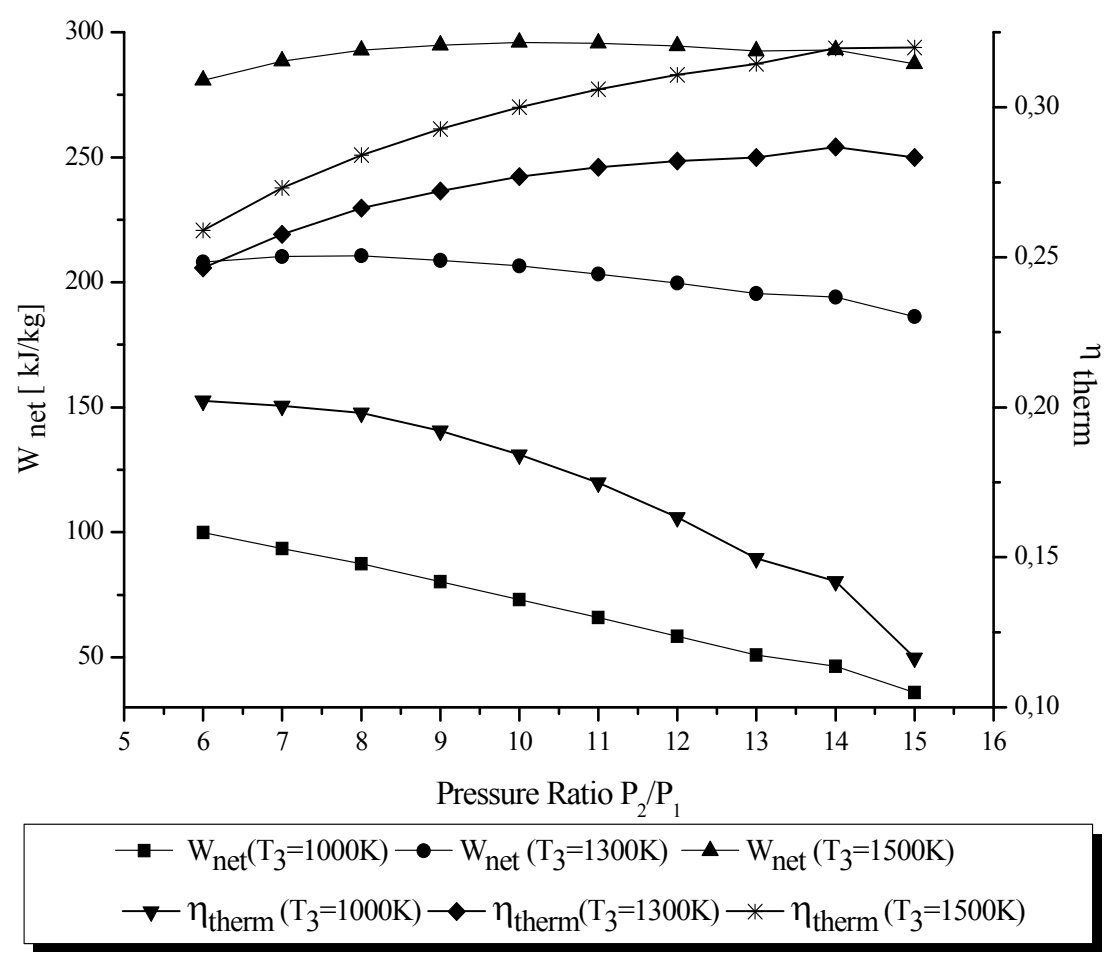

Fig 1 Variation of net work and efficiency at different pressure and temperature ratios

In the results obtained, it can be noted that the net work and efficiency decrease as the pressure ratio increases, when the temperature at which it is analyzed is $1000 \mathrm{~K}$, this reduction is reflected in $8.5 \%$ with respect to the initial conditions. When the temperature of state 3 increases, so does the net work and efficiency to a maximum point and then decreases, making the cycle more efficient by about $12 \%$.

\subsection{Exergy destruction by components}

In order to analyze the amount of exergy that is destroyed in each of the components of the cycle (turbine, compressor and combustion chamber), temperature 3 was variedbetween $1000 \mathrm{~K}$ to $1500 \mathrm{~K}$, increasing the pressure ratio by one unit in the interval $[6,15]$. Similarly, the initial conditions mentioned above were followed.Figure 2 shows the behavior of the exergy destroyed in each component.

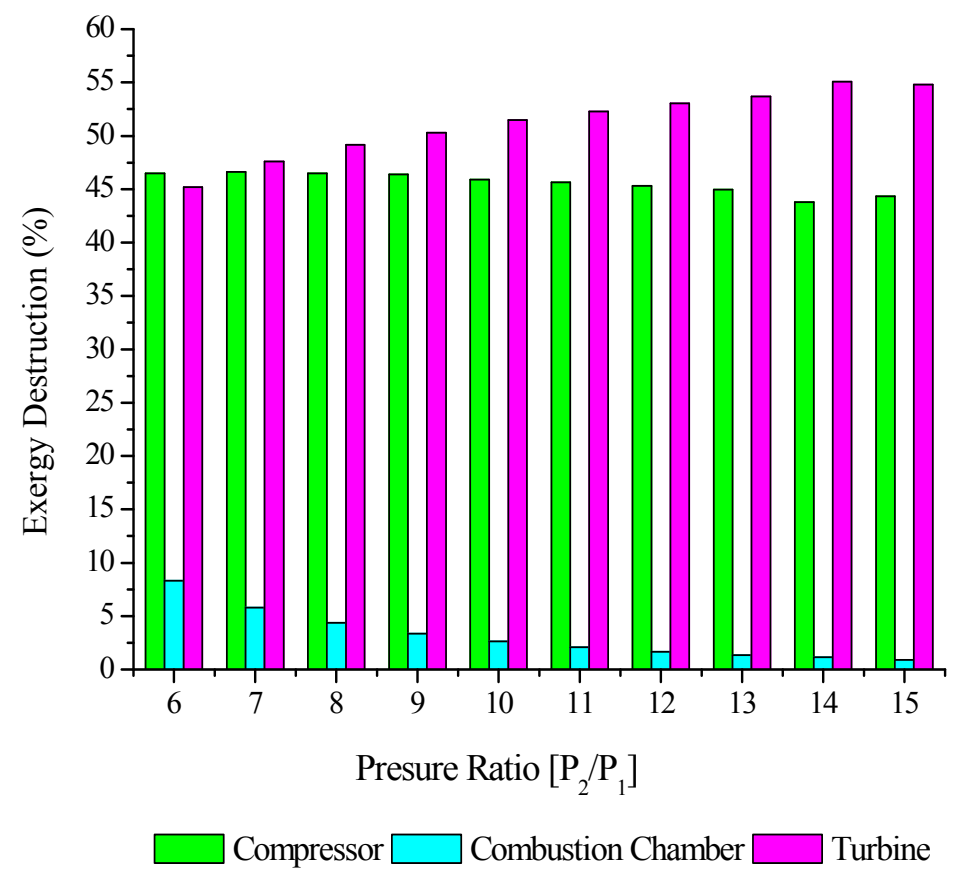

Fig 2. Exergy destroyed by components at $100^{\circ} \mathrm{K}$ temperature 
It can be appreciated that the turbine is the component which destroys most exergy in the cycle from the pressure ratio of 7 , before this the compressor is the one that destroys $46,46 \%$, however, the difference between it and the turbine is insignificant, which is explained because of the large difference in enthalpy and entropy between the inlet and outlet of the turbine. From the data collected by the case study when the inlet turbine temperature is $1300^{\circ} \mathrm{K}$, the exergy destroyed by components is shown in Figure 3.

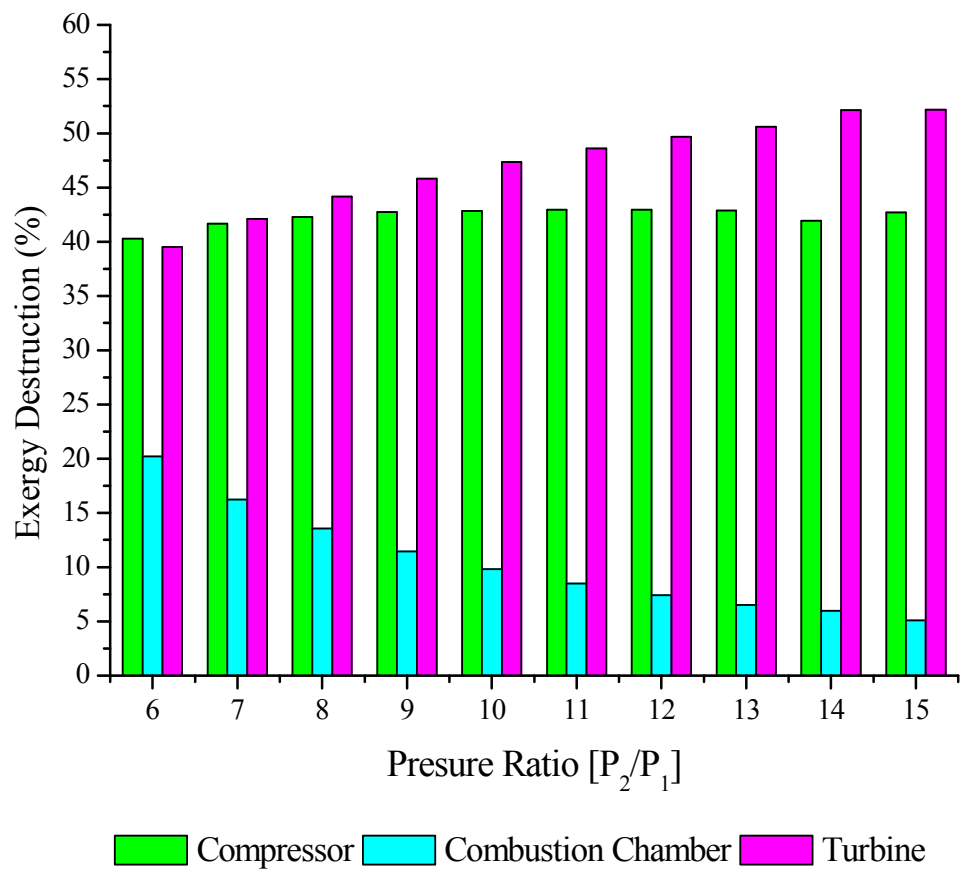

Fig 3 Exergy destroyed by components at $1300^{\circ} \mathrm{K}$ temperature

When temperature 3 is $1300^{\circ} \mathrm{K}$, the turbine keeps being the component with most influence in the destruction of exergy. The compressor destroys more exergy $(40,29 \%)$ when the pressure ratio is6, the turbine is the one leading the exergy destruction. When the analysis temperature is $1500^{\circ} \mathrm{K}$, there results obtained are shown in Figure 4.

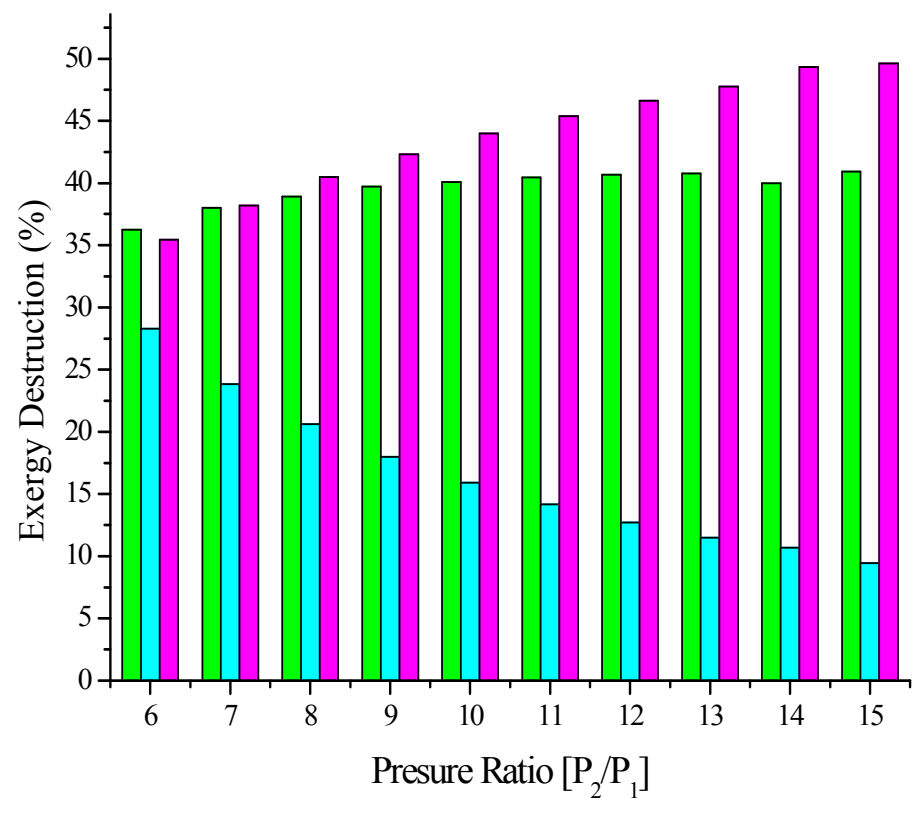

Compressor $\square$ Combustion Chamber $\square$ Turbine

Fig 4 Exergy destroyed by components at $1500^{\circ} \mathrm{K}$ temperature. 
From the previous results, it can be noticed that the turbine destroys more exergy in most cases. At the ratio of 6 , the compressor destroys $0.79 \%$ more exergy than the turbine and from ratio 7 the turbine generates more destruction of exergy. The most exergy destroyed is reflected in the pressure ratio of 15 with a $2,18 \%$ of total exergy destroyed.

\subsection{Behavior of the efficiency of the cycle and of the second law at different pressure ratios}

In order to analyze this case, the pressure ratio has been varied within the range $[6,15]$ at different temperatures $3\left[1000^{\circ} \mathrm{K}, 1300^{\circ} \mathrm{K}, 1500^{\circ} \mathrm{K}\right]$ and the influence in the efficiency of the cycle, based on thethermodynamic second law, obtaining the results shown in Figure 5.

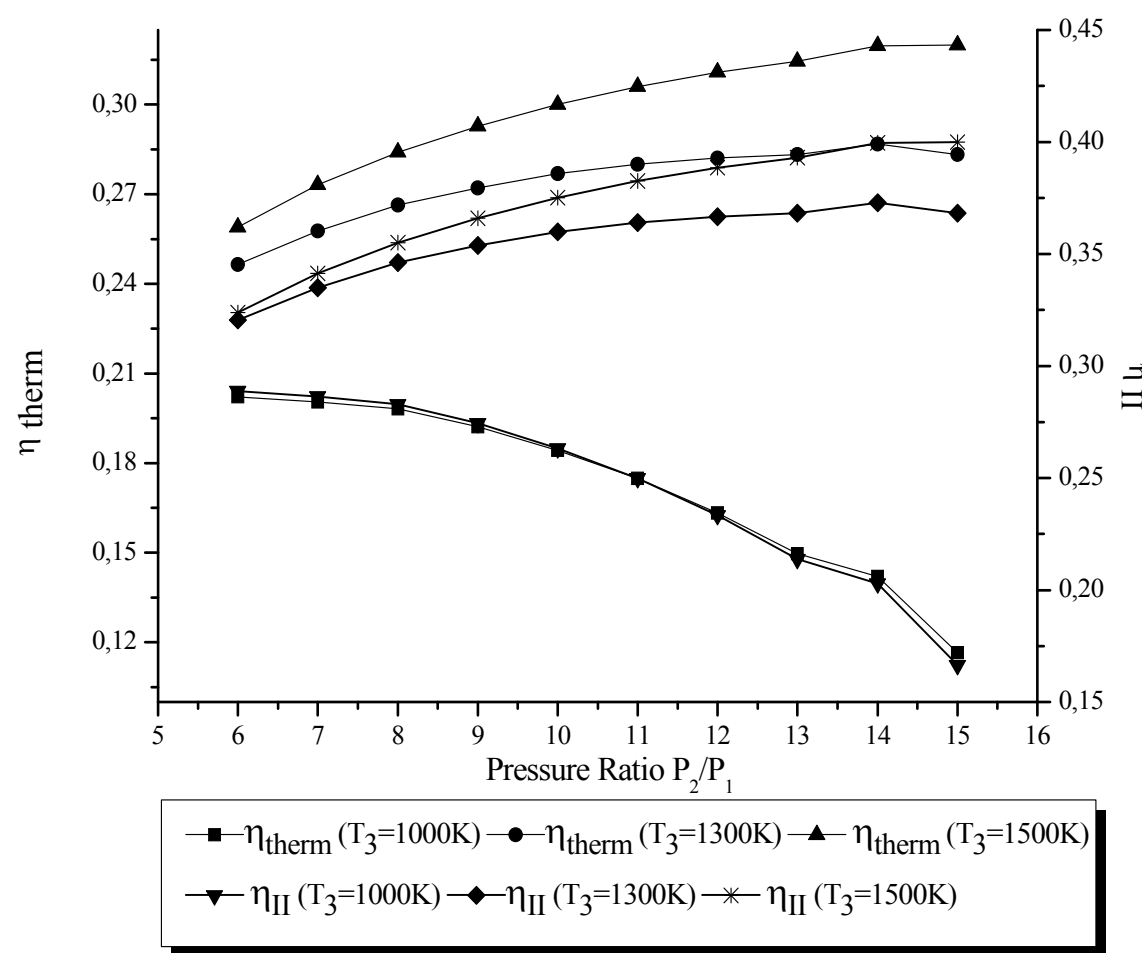

Fig 5. Variation of cycle and second law efficiencies at different pressure and temperature ratios.

From the results obtained, a different behavior for temperature efficiencies of $100 \mathrm{~K}$ with respect to others temperatures can be inferred. While the efficiencies increase proportionally with the increase of pressure ratios between $1330 \mathrm{~K}$ and $1500 \mathrm{~K}$, the opposite occurs for temperatures of $100 \mathrm{~K}$, as the pressure ratio increases the thermal and second law efficiency decrease to $8,55 \%$ and $12,23 \%$ respectively, compared to the initial conditions. When the temperature 3 is $1300 \mathrm{~K}$ and the pressure ratio is 15 , the thermal and second law efficiency increases by $3,6783 \%$ and $4,7818 \%$ according to the pressure ratio of 6 . Also, if the inlet temperature in the turbine is $1500 \mathrm{~K}$, the thermal efficiency increases by $6.098 \%$ and the second-grade increases by $7,623 \%$ comparing the data between pressure ratio 6 and 15 .

\section{CONCLUSIONS}

Doubtless, the software during the student learning process is an essential tool for his training, achieving a better understanding by getting results faster and because of this it could be studied the first and second law of the thermodynamics for the Brayton cycle getting important result for those who operates or are involved in this subject.

If the outlet temperature is higher in the combustion chamber and its pressure ratio is maximum, the cycle efficiency is better. This could be $12 \%$ more efficient compared to the initial conditions. On the other hand, its efficiency will decrease if the outlet temperature is lower and its pressure ratio increases; this decrease by approximately $10 \%$. In addition, a maximum net work is observed when the pressure s 10 and the inlet turbine temperature is $1500 \mathrm{~K}$.

On the other hand, the turbine is the component that destroys more exergy in $90 \%$ of the cases. The next one is the compressor, becoming along whit the turbine the most influential in the destruction of the useful work potential. These ones, destroys between the $70 \%$ and $90 \%$ of the cycle exergy. Finally, the second-grade efficiency showed the same behavior than the cycle, being until $12 \%$ more efficient if the pressure ratio and the combustion chamber outlet temperature were increased.It should be noted that the data provided above can be obtained in other ways and are not exempt from future improvements. 


\section{REFERENCES}

[1] Y. A. Demirel and S. I. Sandler, "Nonequilibrium thermodynamics in engineering and science," J.Phys.Chem.B, vol. 108, no. 1, pp. $31-43,2004$.

[2] C. E. Keutenedjian Mady, M. Silva Ferreira, J. Itizo Yanagihara, P. H. N. Saldiva, and S. Oliveira Junior, "Second law of thermodynamics and human body," Eng. Térmica (Thermal Eng., vol. 10, no. 1, pp. 88-95, 2011.

[3] R. E. English, "Technology for Brayton-Cycle Space Powerplants Using Solar and Nuclear Energy,” NASA, vol. 17, no. 21, 1986

[4] R. Amirante, P. De Palma, E. Distaso, A. M. Pantaleo, and P. Tamburrano, "Thermodynamic analysis of a small scale combined cycle for energy generation from carbon neutral biomass," Energy Procedia, vol. 129, pp. 891-898, 2017.

[5] E. Mariscal-Hay and N. Leon-Rovira, "Electrical generation from thermal solar energy using a turbocharger with the brayton thermodynamic cycle," Energy Procedia, vol. 57, pp. 351-360, 2014.

[6] P. G. Hill and C. R. Peterson, Mechanics And Thermodynamics of Propulsion, Pearson Ed. 1992.

[7] Y. A. CENGEL, Termodinamica, vol. Septima ed. 2011.

[8] M. Moran and H. Shapiro, Fundamentals of Engineering Thermodynamics. 2006.

[9] Y. Haseli, "Optimization of a regenerative Brayton cycle by maximization of a newly defined second law efficiency," Energy Convers. Manag., vol. 68, pp. 133-140, 2013.

[10] Y. Haseli, "Efficiency of irreversible Brayton cycles at minimum entropy generation," Appl. Math. Model., vol. 40, no. 19-20, pp. 8366-8376, 2016.

[11] X. Hao and G. Zhang, "Maximum useful energy-rate analysis of an endoreversible Joule-Brayton cogeneration cycle," Appl. Energy, vol. 84, no. 11, pp. 1092-1101, 2007.

[12] Y. Komatsu, S. Kimijima, and J. S. Szmyd, "Performance analysis for the part-load operation of a solid oxide fuel cell-micro gas turbine hybrid system,” Energy, vol. 35, no. 2, pp. 982-988, 2010.

[13] A. Wark, Advanced thermodynamics for engineers, McGraw-Hil. New York, 1995.

[14] D. Winterbone, Advanced Thermodynamics for engineers, Wiley. New York, 1997.

[15] A. Bejan, Advanced engineering thermodynamics, Wiley. New York, 2006.

[16] M. V. Ledo, F. G. Martínez, and A. R. Piedra, "Software educativos Educational softwares," Rev. Cuba. Educ. Medica Super., vol. 24, no. 1, pp. 97-110, 2010.

[17] S. Castro, B. Guzmán, and D. Casado, "Las Tic en los procesos de enseñanza y aprendizaje," Rev. Científicas América Lat., vol. 13, no. 23, pp. 213-234, 2007.

[18] M. Malaver de la Fuente, "La relación de trabajo de retroceso de un ciclo Brayton," 2010

[19] F. (UPM) Herrero Acebes, J. L. (UPM) Rapun Jimenez, M. C. (UPM) Gonzalez Fernandez, J. M. (UPM) Lacalle Tortola, and R. (UPM) Nieto Carlier, "E-Learning of Thermodynamic Cycles in Engineering: Ciclowin," in International Technology, Education and Development Conference, 2007.

\section{AUTHOR PROFILE}

Nelly A. De Armas Calderon born in Barranquilla, Colombia on January 14th, 1998. She is a student in mechanical engineering at Universidad del Atlántico. In her undergraduate thesis, is working application of linear observers in thermodynamic processes at Universidad del Atlántico.

Guillermo Valencia Ochoa born in Barranquilla, Colombia. Is a full-time professor at the Universidad del Atlántico. Received a degree in Mechanical Engineering from Universidad del Norte, located in Barranquilla, Colombia in 2005. Master in Mechanical Engineering from Universidad del Norte, Barranquilla, Colombia in 2008. Ph. D in Engineering from the Universidad Pontificia Bolivariana, Medellin, Colombia in 2014. He is an assistant professor of the Mechanical Engineering Program, Specialization in Energy Efficient Management and Master in Energy Management at Universidad del Atlántico.

Alfonso Rodríguez Peña is a full-time professor at the Universidad del Atlántico. Received a degree in Mechanical Engineering from Universidad Tecnológica del Bolivar. Master in Mechanical Engineering from Universidad del Norte,Specialization in Productions and Operations at Universidad Autónoma del Caribe, CNC Machining and Hydraulics and pneumatics at SENA-Colombo-Aleman. 